\title{
Experiential Physical Education in a Bilingual Japanese University: Implications for Student Physical Activity and Program Development
}

\author{
Michael Annear ${ }^{1}$, Yasuo Shimizu' ${ }^{2}$, Tetsuhiro Kidokoro ${ }^{3}$ \\ ${ }^{1}$ Faculty of Sport Sciences, Waseda University, Tokyo, Japan \\ ${ }^{2}$ Division of Arts and Sciences, International Christian University, Tokyo, Japan \\ ${ }^{3}$ Physical Fitness Research Institute, Meiji Yasuda Life Foundation of Health and Welfare, Tokyo, Japan \\ Email: annear@aoni.waseda.jp
}

How to cite this paper: Annear, M., Shimizu, Y., \& Kidokoro, T. (2022). Experiential Physical Education in a Bilingual Japanese University: Implications for Student Physical Activity and Program Development. Advances in Physical Education, 12, 11-28. https://doi.org/10.4236/ape.2022.121002

Received: November 30, 2021

Accepted: January 10, 2022

Published: January 13, 2022

Copyright $\odot 2022$ by author(s) and Scientific Research Publishing Inc. This work is licensed under the Creative Commons Attribution International License (CC BY 4.0).

http://creativecommons.org/licenses/by/4.0/

\begin{abstract}
Participation in compulsory physical education (PE) is a controversial aspect of the Japanese university system. English-language education programs in Japanese universities often incorporate aspects of the traditional curricula, including experiential PE. The purpose of the study was to explore the extent to which compulsory $\mathrm{PE}$ in a Tokyo-based global university program contributes to overall physical activity (PA) and to elucidate how experiential PE intersects with student beliefs and motivations. The study sample included 199 domestic and international students attending PE courses in a Top Global University in Tokyo, Japan. All students who undertook compulsory PE classes in English were invited to complete an online survey in 2018-19. Survey measures included scores on a valid and reliable iteration of the Global Physical Activity Questionnaire (GPAQ), self-reports of PA influences, and PA-related health beliefs. Overall PA was high among the cohort, yet there were significant differences based on gender and country of origin, with male and international students reporting higher activity. Most students perceived a positive relationship between PA participation and disease prevention, which reinforced common health motives for activity, particularly weight control and stress reduction. Compulsory and experiential PE within a Japanese global university program potentially contributes to higher PA levels among ethnically diverse undergraduates but should adapt to a more wellness focused curriculum to address behavioral and motivational variations.
\end{abstract}

\section{Keywords}

Cross-Cultural, Global University, GPAQ, Sports Participation 


\section{Introduction}

In the context of growing international enrolments in Japanese universities and ongoing global reductions in physical activity (PA) among younger adults (Warner et al., 2021), this study explored and compared PA behaviours and beliefs among ethnically diverse student cohorts attending compulsory physical education (PE) at a Top Global University (TGU) in Tokyo. The number of international students attending Japanese universities is increasing rapidly in line with trends for the globalization of tertiary education (Rose \& McKinley, 2018). In the decade immediately prior to the COVID-19 pandemic, Japan experienced an annual $10 \%$ increase in international enrolments with over 300,000 foreign students in the country as of 2018 (Japan Student Services Organization, 2019). Reasons for such increases include declining populations of domestic students, the high reputation of Japanese Universities within the Asia-Pacific region, and recent government support to stimulate international engagement with higher education (Hashimoto, 2018; Rose \& McKinley, 2018). Most international students in Japan are from comparatively developed nations in the Asia-Pacific or North America and many are enrolled in bilingual or English-language courses implemented as part of the TGU program. The Japanese government launched the TGU program in 2014 involving 37 public and private universities to increase international competitiveness and compatibility (MEXT, 2020). The 37 TGUs receive funding to provide globally oriented programs that often incorporate elements of the formal Japanese education system, including compulsory PE.

The focus of this research is underpinned by ongoing debates about the place of PE in Japanese universities and a lack of academic research concerning the globally oriented TGU program. More than $40 \%$ of Japanese universities require undergraduate students to complete compulsory courses in PE, including many universities within the TGU program (National Institute of Physical Education, 2018). Such requirements are unique to Japan and not mandated in international universities where students typically complete formal PE requirements during high school. Compulsory PE in Japanese universities is an experiential education subject wherein students participate in supervised sports or exercise sessions that aim to promote general health, socialization, acclimation to university life, and communication skills (Izumo et al., 2007). There are some similarities with reported elements in the Chinese tertiary education system, although PE and sport participation opportunities are more commonly elective options rather than compulsory subjects (Hastie et al., 2020). Recently, compulsory PE has become a controversial issue in Japan and the subject of pedagogical debate. For instance, in a recent survey of 109 universities, more than $15 \%$ reported that they had removed compulsory PE requirements in the last decade following changes to national standards for core undergraduate curricula (National Institute of Physical Education, 2018; Wei et al., 2012). Despite this change, many universities in Japan still require undergraduates to complete mandatory courses in PE before 
they are eligible to graduate. While contested, the inclusion of PE as a compulsory undergraduate subject is potentially relevant in the $21^{\text {st }}$ Century considering the ongoing obesity epidemic that is affecting diverse cohorts in developed nations (James, 2008) and long-term trends for reductions in cardiorespiratory fitness and PA among young people in Japan and abroad (Matsushita et al., 2004; Tomkinson et al., 2019).

To date, there have been no studies undertaken that seek to assess PA parameters among ethnically diverse cohorts of undergraduate PE students in Japan using reliable and valid measures. University students provide a fruitful cohort for investigation as they are in a transitional phase between childhood and adulthood with many demands on their time, attention, and behaviour. International and domestic research suggests that university is often a time when students begin a transition away from active lifestyles (Kwan et al., 2012), which makes it an important context for investigation. A focus on university students is also important because life course research shows that the PA behaviours established during early adulthood significantly predict PA and health outcomes later in life through associations with PA experiences, skill development and self-efficacy (Hirvensalo \& Lintunen, 2011). Several reliable and valid scales have been developed to assess self-reported PA among diverse age cohorts, including young adults. Among such measures, the Global Physical Activity Questionnaire (GPAQ) (Armstrong \& Bull, 2006), developed under the auspices of the World Health Organization (WHO), provides acceptable cross-cultural interpretation with administration across a variety of modalities (e.g., self-completed, interviewer administered, and online) (Castro et al., 2019; Stelmach, 2018). International studies have been undertaken of university students' PA behaviours in the last decade using valid and reliable measures (including the GPAQ) in Thailand, India, Indonesia, Singapore, and Spain (Acebes-Sánchez et al., 2019; Chu et al., 2015; Rizki \& Rachman, 2019; Shah et al., 2016; Wattanapisit et al., 2016). There remains limited scholarship that has examined this issue in the context of increasingly diverse student cohorts in Japan.

The aim of the present study was to explore and compare PA behaviours, motivations and beliefs among an ethnically diverse cohort of male and female university students attending a compulsory PE program at a TGU in Tokyo, Japan. The TGU setting creates a unique natural experiment with high numbers of Japanese and overseas-born students enrolled and participating in weekly PE classes as part of their bachelor's degree program. The implicit hypothesis is that there are likely to be significant PA differences based on cultural background and gender among undergraduate students attending PE in a bilingual program that potentially reflect educational and socio-cultural backgrounds and expectations. Moreover, it is also predicted that students will have a diversity of motives for PA that may not currently be well aligned with existing and sport-dominant PE program structure. By measuring and comparing PA characteristics among cohorts of international and Japanese university students we may gain informa- 
tion to assist in adapting and improving globally oriented university PE programs to make them more relevant for changing student populations with diverse activity needs and expectations in the $21^{\text {st }}$ century. Such research also helps to assess the value of PE as a core part of university curricula in Japan to address ongoing debates about its place in higher education.

\section{Methods}

\subsection{Design and Theory}

The study was designed as exploratory cross-sectional survey research (Creswell, 2014) as it is the first investigation of its kind undertaken in Japan with an ethnically diverse cohort of English-speakers attending an internationally oriented PE program. An online survey methodology was used to facilitate efficient data collection, and information was gathered using Google Forms and Moodle 3.5 educational software. Study conception and design were informed by the Health Belief Model (Champion \& Skinner, 2008) of human behavior derived from the Public Health and Health Marketing literature. The Health Belief model (Champion \& Skinner, 2008) is a long-standing intra-personal theory of human behaviour, which hypothesizes that PA participation (and similar preventive behaviors) is often motivated by desires to improve health or reduce lifetime disease risk (Champion \& Skinner, 2008). PA participation is considered to be a complex behavior that is influenced by such factors as health motivation, self-efficacy (confidence in one's ability to perform a desired behavior), knowledge, and perceived benefits of and barriers to action (Champion \& Skinner, 2008; Shafiei et al., 2018).

\subsection{Participants}

The student sample included all undergraduates in an English-language PE program at a bi-lingual TGU in Tokyo, Japan. The PE program at the target university is mandatory, so selection of all course attendees provided a representative cross-section of undergraduate students. In principle, all enrolled students who were physically capable of attending physical education class (i.e., they had no medical exclusion) were included in the participant sample. Students were excluded from selection if they were unwell or injured at the time of the study. Participants included a spectrum of students who expressed a wide variety of PA behaviors and beliefs (not only active students). All enrolled students were invited to participate in the first week of PE class participation with two verbal follow-up reminders provided by the lead researcher. Surveys were conducted during the Spring and Autumn semesters when the weather is relatively settled and amenable to outdoor PA participation in Tokyo (i.e., to control for the possible influence of extreme weather conditions). Student participation was voluntary and not linked to course grade. Prior to participation, students were informed of study aims and notified that submission of the online survey form represented consent for the reporting of anonymous and aggregated data. All 
respondents had native-level English fluency or a high level of English as second language based on University entrance requirements (TOEFL score > 79; IELTS > 6.5). The study was reviewed and approved by an institutional human research ethics committee (reference number: 2017-23).

\subsection{Measures}

The English-language Global Physical Activity Questionnaire (GPAQ) was the primary measure for collecting information on moderate and vigorous PA across the domains of work, travel, and recreation (Armstrong \& Bull, 2006). The GPAQ is one of the leading international scales that have been designed to accurately assess habitual physical activity participation across multiple countries and regions. The tool was developed by the World Health Organization (WHO) and has demonstrated acceptable reliability and validity in nine countries (test-retest reliability $0.67-0.81$; concurrent validity, $r=0.65$ ) (Armstrong \& Bull, 2006). The GPAQ was also used to elucidate levels of sedentary behaviour (sitting time) among ethnically diverse student cohorts. Potential influences on PA were identified from international systematic reviews of the correlates of young adult health behaviour (Sallis et al., 2000; Sterdt et al., 2014) undertaken in the last two decades. In total, 23 potential correlates were summarized (across intrapersonal, interpersonal, and environmental domains) and presented to respondents as either possible barriers $(n=9)$ or possible motivators $(\mathrm{n}=12)$ of PA. Health beliefs were measured using an adapted, single-item scale that was based on the Health Beliefs Model (Champion \& Skinner, 2008), which asked students to report their beliefs concerning the connection between regular PA and risk of developing chronic disease. Finally, students were asked to provide demographic details such as age, gender, academic year-level, and country of birth (see Table 1).

\subsection{Analysis}

Prior to the establishment of the analytical approach, sample size calculations were performed to provide a sound basis for comparative statistics. Sampling was undertaken to exceed the power requirements for comparative inferential tests as determined by $\mathrm{G}^{\star}$ Power software ( $>134$ total subjects for comparative parametric tests, with a confidence interval of $95 \%$ and an alpha level of <.05) (Faul et al., 2009). Following data cleaning, the distributions of main outcome variables were investigated to determine appropriate tests of significance. GPAQ variables were positively skewed, so median and percentile values were used to describe the data and non-parametric tests of significance were employed, including the Mann-Whitney U tests, Chi-square tests and Spearman's correlation. Analysis of GPAQ data followed guidelines published by the WHO (2010) and recommended cut points for low active ( $<600$ Met-minutes per week), moderately active (600 - 2999 Met-minutes per week), and highly active (>3000 Met-minutes per week). The primary outcome of interest (PA level measured in 
MET-minutes per week) was based on previously published procedures and WHO guidelines for energy expenditure at different exercise intensities over a period of seven days (WHO, 2010). Additionally, analytic tests performed in this study mirrored strategies undertaken in studies of university student PA undertaken with similarly sized populations in other countries (Acebes-Sánchez, et al., 2019; Chu et al., 2015; Rizki \& Rachman, 2019; Shah et al., 2016; Wattanapisit et al., 2016). Influences on PA included an assessment of social-ecological barriers and motivators that included 23 individual, interpersonal and environmental factors that identified from systematic reviews of known correlates of younger adult PA behaviour (Sallis et al., 2000; Sterdt et al., 2014) and conforming to the previously described Health Belief Model (Champion \& Skinner, 2008). Students were asked to select one main barrier and one main motivator that they felt had a significant influence on their PA participation. Descriptive and Chisquare tests for independence were used to assess these data. The measurement of student health beliefs was based on a single item measure adapted from Champion \& Skinner (2008)'s Health Belief Model; How important do you think regular physical activity participation is for preventing chronic diseases (diseases that develop slowly over your life such as heart disease)? Student health beliefs were assessed using a five-point Likert scale and descriptive and Mann-Whitney U statistics. All results were performed using SPSS (version 23) statistical software.

\section{Results}

During the Spring and Autumn semesters of 2018-19, 199 undergraduate student volunteers (70\% response rate among 285 invited students) at a TGU in Tokyo completed an online survey of their PA behaviors, motivations, and beliefs. Surveys were undertaken during a period of seasonally mild weather and prior to the emergence of the global COVID-19 pandemic. Following completion of surveys, data were automatically output from Google Forms to an Excel file before conversion into an SPSS database for cleaning and screening. All data were checked for erroneous values, missing data, and duplicate cases before analysis and reporting of results. Reasons for non-participation were not articulated by those who chose not to respond to the survey. Demographic characteristics of the respondent cohort are summarized in Table 1 below.

\subsection{Total Weekly Activity Participation}

The primary outcome measure in this study was total weekly activity participation represented as total weekly energy expenditure attributable to physical activity and reported in Met-minutes per week based on GPAQ data processing guidelines (WHO, 2010) (see Figure 1). Secondary outcome measures (reported below) included moderate and vigorous activity as well as participation in specified activity domains, including manual work, active transport, and recreation over a typical week. Median total weekly activity among the student cohort was 
3240 Met minutes per week (Interquartile range $(I Q R)=5040)$. Across the cohort, $14 \%$ of students were classified as low active (inactive) with $<600 \mathrm{Met}$-minutes per week, 35\% were moderately active (600 - 2999 Met-minutes per week), and 51\%

Table 1. Demographic characteristics of PE student cohort.

\begin{tabular}{lcc}
\hline Demographic parameter & \multicolumn{2}{c}{ Statistic } \\
\hline Age & 21 & $(S D=2)$ \\
$\quad$ Mean and SD & 7 & $(18-25)$ \\
$\quad$ Range & & \\
Gender & 75 & $(38 \%)$ \\
$\quad$ Male & 124 & $(62 \%)$ \\
Female & & \\
Undergraduate year level & 179 & $(90 \%)$ \\
$\quad$ First year & 13 & $(6.5 \%)$ \\
Second year & 3 & $(1.5 \%)$ \\
Third year & 4 & $(2 \%)$ \\
Fourth year & & \\
Nationality & & $(12 \%)$ \\
Japan (domestic) & 110 & $(45 \%)$ \\
International & 89 & $(51 \%)$ \\
United States & 45 & $(15 \%)$ \\
China & 13 & \\
South Korea & & \\
Other (Asia-pacific region) & & \\
\hline
\end{tabular}

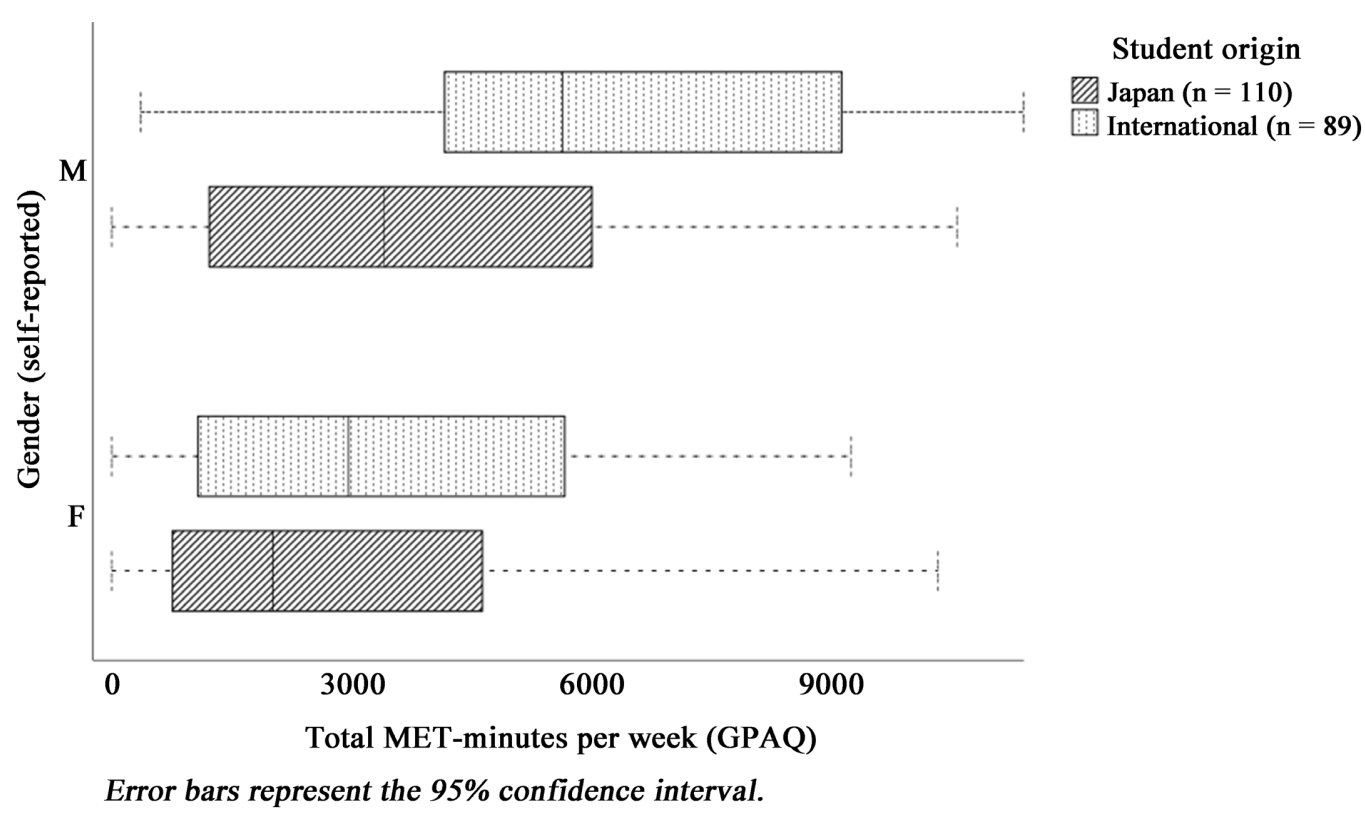

Figure 1. Total weekly student activity by gender and country of origin. 
Table 2. Percentile values for intensity and mode of physical activity participation.

\begin{tabular}{|c|c|c|c|c|c|}
\hline \multirow{2}{*}{\multicolumn{2}{|c|}{ Activity intensity and mode }} & \multicolumn{4}{|c|}{ Percentiles (Met-minutes per week) } \\
\hline & & \multirow{2}{*}{$\begin{array}{c}25 \\
560\end{array}$} & \multirow{2}{*}{$\begin{array}{c}50 \\
1460\end{array}$} & \multirow{2}{*}{$\begin{array}{c}75 \\
2760\end{array}$} & \multirow{2}{*}{$\begin{array}{c}95 \\
6840\end{array}$} \\
\hline Moderate activity & Japanese & & & & \\
\hline & International & 900 & 2640 & 4800 & 10,080 \\
\hline & Male & 720 & 2160 & 4440 & 10,080 \\
\hline & Female & 694 & 1760 & 3600 & 7200 \\
\hline \multirow[t]{4}{*}{ Vigorous activity } & Japanese & 0 & 0 & 2880 & 7200 \\
\hline & International & 0 & 480 & 2880 & 8160 \\
\hline & Male & 0 & 1920 & 3600 & 7760 \\
\hline & Female & 0 & 0 & 1440 & 7680 \\
\hline \multirow[t]{4}{*}{ Work activity } & Japanese & 0 & 0 & 600 & 4320 \\
\hline & International & 0 & 560 & 1920 & 8400 \\
\hline & Male & 0 & 280 & 1920 & 8640 \\
\hline & Female & 0 & 70 & 1080 & 4320 \\
\hline \multirow[t]{4}{*}{ Active transport } & Japanese & 300 & 800 & 1440 & 3360 \\
\hline & International & 360 & 840 & 2400 & 5760 \\
\hline & Male & 300 & 800 & 2100 & 6000 \\
\hline & Female & 310 & 820 & 1470 & 3600 \\
\hline \multirow[t]{4}{*}{ Recreation activity } & Japanese & 0 & 480 & 2880 & 6720 \\
\hline & International & 0 & 1440 & 3040 & 10,080 \\
\hline & Male & 240 & 1440 & 4080 & 7200 \\
\hline & Female & 0 & 360 & 2320 & 8640 \\
\hline \multirow[t]{4}{*}{ Total activity } & Japanese & 880 & 2340 & 5280 & 10,320 \\
\hline & International & 1600 & 4320 & 6720 & 18,720 \\
\hline & Male & 2160 & 4260 & 7000 & 16,680 \\
\hline & Female & 860 & 2280 & 5160 & 12,840 \\
\hline
\end{tabular}

were highly active (>3000 Met-minutes per week). Total weekly energy expenditure was also calculated for three activity typologies: work-related (e.g., manual part-time jobs), active transport (e.g., walking or cycling to university) and recreational (e.g., sport or exercise participation). Across the sample, work-related PA contributed to a median of 240 Met-minutes per week (14\% of total activity), active transport contributed 800 Met-minutes (45\% of total activity), and recreational activity contributed 720 Met-minutes (41\% of total activity). Across all activity levels and domains, international students (Median $=4320$ met minutes per week) were significantly more active than those born in Japan (Median = 2340 met minutes per week), $\mathrm{U}=6056, \mathrm{z}=2.87, p=0.004$. Male students (Me- 
dian $=4260)$ were also significantly more active than female students (Median $=$ 2280), $\mathrm{U}=3307, \mathrm{z}=3.41, p=0.001$ (see Table 2).

\subsection{Moderate Activity Participation}

Median moderate activity was 1840 Met-minutes per week $(I Q R=3132)$. Moderate activity participation was significantly higher among international students $($ Median $=2640)$ compared to those who were born in Japan $($ Median $=1460), \mathrm{U}$ $=6333, \mathrm{z}=3.56, p<0.001$. Moderate-level activity participation was comparable across male and female respondents with no significant differences observed.

\subsection{Vigorous Activity Participation}

Vigorous activity participation was very low across the cohort, and the group median was 160 Met-minutes per week $(\mathrm{IQR}=2880)$. Male students were significantly more likely to participate in vigorous activity (Median $=1920)$ compared to female students (Median $=0$ ), $\mathrm{U}=3401, \mathrm{z}=3.37, p=0.001$. There was not a significant difference in vigorous activity participation by country of origin.

\subsection{Physical Activity Domains}

Male students were more active than females in recreational activities (including sport), which supports findings for gender differences in vigorous activity, $\mathrm{U}=$ $3488, \mathrm{z}=-3.01, p=0.003$. There was no significant difference in recreational PA between Japanese and international students. International students were more active than Japanese students in relation the work-related domain (including manual labor), $\mathrm{U}=6039, \mathrm{z}=3.00, p=0.003$. There was no significant difference in work-related activity participation by gender. There were no variations by gender or country of origin in terms of the active transport domain.

\subsection{Daily Sitting Time}

Students spent a median of 420 minutes ( 7 hours) per day sitting. Across the cohort, $28 \%$ sat for less than 6 hours per day, 25\% sat for between 6 and 8 hours and $47 \%$ sat for more than 8 hours. There was a significant difference in reported sitting times based on country of origin. Reported sitting was significantly higher among international students (Median $=480$ minutes) compared to those born in Japan (Median $=390$ minutes), $\mathrm{U}=5806, \mathrm{z}=2.27, p=0.02$. There were no significant gender differences in reported sitting time. Sitting time was not significantly correlated with total PA or activity subdomains.

\subsection{Health and PA Beliefs}

Students were asked how important they believed regular PA is for the prevention of chronic health conditions, such as cardiovascular disease, by answering a question adapted from the international epidemiological literature. Students identified a strong connection between chronic disease prevention and regular $\mathrm{PA}$, scoring $4.48(\mathrm{SD}=0.72)$ on a five-point Likert-type scale running from not 
important (1) to very important (5) (93\% of respondents rating the statement 4 or higher). Based on Mann-Whitney U statistic, this belief was found to be consistent across the entire cohort, irrespective of country of origin $(U=5287, z=$ $1.11, p=0.27)$ or gender $(\mathrm{U}=4466, \mathrm{z}=-0.53, p=0.59)$. Higher scores concerning beliefs about the connection between health and PA participation were significantly correlated with increased moderate activity participation ( $r s=0.16$, $p=0.02$ ), although not with sitting time, vigorous or total PA.

\subsection{Barriers and Facilitators of PA}

Drawing on international literature review evidence concerning common influences on PA in younger adult populations, several salient barriers and facilitators were identified across the target cohort. Lack of time (35\% of responses) and low motivation ( $31 \%$ of responses) were the main barriers to PA among the student cohort, and $10 \%$ of respondents reported no barriers to their activity participation (i.e., they were as active as they wished to be). Based on a Chi-square assessment, reported barriers were consistent across gender $\left(\chi^{2}=12.18\right.$, Cramer's $\mathrm{V}=0.25, p=0.14)$ and country of origin $\left(\chi^{2}=\right.$, Cramer's $\mathrm{V}=0.18, p=$ 0.63).

Health improvement (including weight management, disease prevention or stress management) was the dominant motivator of PA for respondents (32\% of responses). Lesser facilitators included social interaction (11\%) and self-confidence (11\%). Based on a Chi-square assessment, reported facilitators were also consistent across gender $\left(\chi^{2}=8.96\right.$, Cramer's $\left.\mathrm{V}=0.21, p=0.63\right)$ and country of origin $\left(\chi^{2}=8.49\right.$, Cramer's $\left.\mathrm{V}=0.21, p=0.67\right)$. These results suggest that there are no significant gender or ethnic differences in terms of commonly reported influences on PA within a university student sample.

\section{Discussion}

\subsection{Student Activity Patterns}

The majority of students undertaking compulsory PE at a TGU in Japan are meeting WHO guidelines for PA, with only a small proportion classified as low-active (i.e., inactive to a degree that it is considered a health risk). Data from the current study compare favorably to international investigations. Considerably more of our cohort achieved international PA recommendations compared to published reports of undergraduate cohorts in Spain, Indonesia, and Thailand (Acebes-Sánchez et al., 2019; Rizki \& Rachman, 2019; Wattanapisit et al., 2016). It appears probable that a weekly session of 90 minutes of compulsory PE contributes positively to meeting baseline PA guidelines among students who attend a TGU, particularly recreational PA (e.g., sport or exercise participation). This is evidenced by the observation that the median Met-minutes per week for the sample narrowly exceeded the WHO cut point for high-active ( $>3000$ Met-minutes per week). Without a PE class, it is possible that students would report a significantly lower median activity level (within the active or low-active range). How- 
ever, it is also important to note that the greatest contribution to weekly PA among undergraduates came from active transport (e.g., walking and cycling for utilitarian reasons). Preferences for active travel may be explained by environmental conditions in the study setting. In international comparative terms, Japanese urban areas, including Tokyo, are supportive of active transport and offer high levels of perceived safety and appropriate infrastructure. For instance, Tokyo recently ranked first among 60 cities on the global Safe Cities Index (Economist Intelligence Unit, 2019), which included measures of pedestrian friendliness, public transport access and perceptions of environmental safety.

Despite a relatively high level of overall PA compared to international studies, significant differences emerged by gender and country of origin. Male and international students reported higher activity levels compared to those born in Japan and female students. The gendered nature of PA participation, particularly vigorous activity, has previously been reported among cohorts of undergraduates from North American and British Universities (Aceijas et al., 2016; Buckworth \& Nigg, 2004; Suminski et al., 2002). Reasons for this variation that have been offered include comparatively limited role models in women's sport or fewer social sports groups for females at a university (Buckworth \& Nigg, 2004; Suminski et al., 2002). This difference may also reflect the popularity of university sports clubs and circles (informal student groups based on mutual interest) in Japan, which typically provide expanded opportunities for male participation. Indeed, female participation has been shown to be around 35\% lower in education-based sports clubs in Japan, which provide limited opportunity for female competition and inculcate traditional notions of gender-appropriate sports (Hartmann-Tews \& Pfister, 2003). The gendered nature of sport and exercise in Japan, with preferential treatment and differential opportunities for male students, is a long-stranding social issue, which is becoming a subject of national and international debate in a historically patriarchal society (Hartmann-Tews \& Pfister, 2003).

Beyond gender differences, there were also variations in PA based on country of origin. International students were significantly more active than their Japanese peers with regards to both total and moderate PA. Based on WHO cut points WHO (2010), the data suggest that international students are typically highly active ( $\geq 3000$ met-minutes per week) compared to Japanese students who are typically moderately active (600 - 2999 met-minutes per week). Lower levels of activity among the Japanese cohort may be explainable by consistent declines that have been reported in annually assessed fitness parameters among young people (and other age cohorts) in Japan. For example, trends in hand grip strength and step count have shown persistent declines among young Japanese adult populations in declines since the 1980s (Kidokoro et al., 2020; Tanaka, 2019). International studies, however, have also shown general temporal declines in PA among younger adult and student cohorts in recent decades (Caspersen et al., 2000; Telama \& Yang, 2000). In the context of widespread PA and fitness de- 
clines, therefore, higher levels of activity among international students in the present study may reflect certain physiological, behavioral, or environmental characteristics experienced by individuals who choose to travel abroad for education. These may be related to higher self-efficacy or socio-cultural factors, which have previously been identified as determinants of PA behaviour (Bauman et al., 2012; Trost et al., 2002). Domain-level analysis also showed that international students reported more work-related physical activity, which may equate higher involvement in part-time employment or manual occupations outside of the educational setting.

Despite overall high levels of activity, student sitting time was also high at 7 hours per day. International research indicates that sitting for 6 or more hours per day is associated with the increased lifetime risk of developing cardiovascular disease (Stamatakis et al., 2019). This may be an area for educational or environmental intervention among the student cohort as sitting behaviour, if sustained over the life course, could lead to premature morbidity and mortality from middle age (Dempsey et al., 2020). Problematic sitting times appear to be partly explained by differences between Japanese and international students. International students within the sample sat for 8 hours per day, while Japanese students sat for only 6.5 hours. While both cohorts are within risk parameters for cardiovascular disease, sitting 8 hours or beyond also places the international cohort at higher risk from all-cause mortality, particularly if this behavioral pattern is continued into middle age (Ekelund et al., 2019; Stamatakis et al., 2019). International students' behavioral patterns could be described as highly active and highly sedentary, while Japanese students could be described as moderately active and moderately sedentary. Higher sitting times among international students may reflect a different pattern of underlying behaviour influenced by upbringing, environment in home country, or a compensatory effect whereby higher levels of total exertion are followed by prolonged periods of inactivity (Gomersall et al., 2013).

\subsection{Health Beliefs and Influences on PA Participation}

Students responded positively to a statement concerning the connection between chronic disease and regular PA, although this belief was only correlated with moderate-level participation. This is relevant, however, as moderate PA (e.g., walking, cycle commuting or dancing) is associated with reduced morbidity and mortality at a population level (Lee \& Paffenbarger Jr., 2000; Saint-Maurice et al., 2019). Moreover, moderate-level activity reflects an intensity that can be sustained by most people across the life course (Saint-Maurice et al., 2019), as well as affording mental health and cognitive benefits (Mota-Pereira et al., 2011). Student recognition of the importance of regular activity for preventing chronic disease and maintaining health was reinforced by self-report data concerning their motivations for being active. Concern about their health (including weight management, disease prevention and stress reduction) was the overarching mo- 
tivating factor for students when they chose to be active. International research concerning the determinants of PA among younger adult cohorts has previously reported health motives to be a prominent behavioral determinant (Egli et al., 2011; Kilpatrick et al., 2005). Students' health motives for PA participation also correspond to predictions of the Health Belief Model (Champion \& Skinner, 2008) and suggest that a focus on wellness, rather than competitive sports, may be desirable to enhance the relevance of university PE in Japan.

Students also reported salient barriers that hindered their PA participation. Lack of time and low motivation constituted the main barriers among English-speaking undergraduates. These barriers are consistent with international research findings concerning constraints to health behaviour among university cohorts and may reflect a range of competing responsibilities for study, parttime work, peer-group participation, and hobbies (Aceijas et al., 2016; Deliens et al., 2015). Lack of time and motivation underlines the potential importance of mandatory PE classes in Japanese universities as these are programmed directly into students' weekly timetables and do not require intrinsic motivation to initiate participation. Such programs contribute to the overall quantum of PA for university students irrespective of personal or environmental barriers as well as increasing sport and recreation experiences (so-called activity repertoires). Interestingly, student respondents in a European study of PA behaviour independently suggested mandatory PE as part of their university curricula to increase activity participation due to time and self-discipline barriers (Deliens et al., 2015).

\subsection{Limitations and Future Research Opportunities}

The present study is exploratory and representative of one university in Japan that is part of the small, but growing, TGU program. Although less than $10 \%$ of Japanese universities currently participate in the TGU program, ongoing increases in international student enrolments are projected in the coming decades (Japan Student Services Organization, 2019). The next step for this research, therefore, is to explore international and domestic student experiences in similar institutions that also have mandatory PE programs as part of a future multi-site investigation. This will be important in anticipation of future expansions of foreign student engagement with the Japanese university system and PE programs. Future research should also examine the psychological and behavioral characteristics of international students in TGUs for comparison with samples of aged-matched controls in their countries of origin. Such research may help to elucidate whether differences between Japanese and international students reflect socio-cultural variations between these cohorts or psychological traits of individuals who travel abroad for education (i.e., an active or adventurous disposition or higher exercise self-efficacy resulting from a diversity of activity experiences).

\subsection{Implications for PE Curricula in Global Education Programs}

The present data suggest that Japanese university PE is a potentially positive 
contributor to adequate and comparatively high levels of PA among domestic and international students attending a TGU. While mandatory PE participation at university level is novel for many international students, it also appears to be beneficial based on reported PA levels, health beliefs, and behavioral influences. The data suggest that for university PE to be most effective in a TGU setting, it should be based on the Health Belief Model of behaviour change and reflect students' prevailing interests in their physical and mental wellbeing. In practice, this could mean offering classes that cater for health management, providing knowledge about exercise physiology and prescription, and building diverse exercise experiences and repertoires that includes less vigorous and more inclusive activity options (e.g., yoga/tai chi, Paralympic sports, and adapted modes of PE) to support activity participation across the life course. Compulsory PE also helps to overcome reported barriers related to time and motivation, which are also reflected in data collected from student cohorts in international research (Aceijas et al., 2016; Deliens et al., 2015). Variations in activity levels and styles between male and female students reported in this study corroborate international data (Aceijas et al., 2016; Buckworth \& Nigg, 2004; Suminski et al., 2002) and suggest that university PE needs to adapt to a broad-based health and wellness model, rather than simply providing a venue for participation in vigorous sports, which appear to be more popular among male study participants. Finally, the potential for cultural exchange offered by TGU programs may facilitate discussions about healthy lifestyles and activity patterns between ethnically diverse student cohorts. For example, in the present study, international students reported higher levels of activity, but this was balanced with equally high rates of sitting. Alternatively, Japanese students reported moderate-levels of PA with correspondingly moderate levels of sedentary behaviour. Over time, diverse peer-group interactions, and growing awareness of the heterogeneity of activity styles, may positively influence student PA behaviors and lifestyle choices within an increasingly multi-cultural educational setting. The results of this study will hopefully stimulate critical discussion and future research concerning the value of experiential physical activity within university curricula.

\section{Conflicts of Interest}

The authors declare no conflicts of interest regarding the publication of this paper.

\section{References}

Acebes-Sánchez, J., Diez-Vega, I., \& Rodriguez-Romo, G. (2019). Physical Activity among Spanish Undergraduate Students: A Descriptive Correlational Study. International Journal of Environmental Research and Public Health, 16, 2770. https://doi.org/10.3390/ijerph16152770

Aceijas, C., Bello-Corassa, R., Waldhäus, S., Lambert, N., \& Cassar, S. (2016). Barriers and Determinants of Physical Activity among UK University Students. European Journal of Public Health, 26, 430. https://doi.org/10.1093/eurpub/ckw174.255 
Armstrong, T., \& Bull, F. (2006). Development of the World Health Organization Global Physical Activity Questionnaire (GPAQ). Journal of Public Health, 14, 66-70. https://doi.org/10.1007/s10389-006-0024-X

Bauman, A., Reis, R., Sallis, J., Wells, J., Loos, R., Martin, B., \& Lancet Physical Activity Series Working Group (2012). Correlates of Physical Activity: Why Are Some People Physically Active and Others Not? The Lancet, 380, 258-271. https://doi.org/10.1016/S0140-6736(12)60735-1

Buckworth, J., \& Nigg, C. (2004). Physical Activity, Exercise, and Sedentary Behavior in College Students. Journal of American College Health, 53, 28-34. https://doi.org/10.3200/JACH.53.1.28-34

Caspersen, C., Pereira, M., \& Curran, K. (2000). Changes in Physical Activity Patterns in the United States, by Sex and Cross-Sectional Age. Medicine \& Science in Sports \& EXercise, 32, 1601-1609. https://doi.org/10.1097/00005768-200009000-00013

Castro, A., Gaupp-Berghausen, M., Dons, E., Standaert, A., Laeremans, M., Clark, A. et al. (2019). Physical Activity of Electric Bicycle Users Compared to Conventional Bicycle Users and Non-Cyclists: Insights Based on Health and Transport Data from an Online Survey in Seven European Cities. Transportation Research Interdisciplinary Perspectives, 1, 1-10. https://doi.org/10.1016/j.trip.2019.100017

Champion, V. L., \& Skinner, C. S. (2008). The Health Belief Model. In K. Glanz, B. Rimer, \& K. Viswanath (Eds.), Health Behavior and Health Education: Theory, Research, and Practice (pp. 45-65). Jossey Bass.

Chu, Anne H., Ng, S., Koh, D., \& Müller-Riemenschneider, F. (2015). Reliability and Validity of the Self- and Interviewer-Administered Versions of the Global Physical Activity Questionnaire (GPAQ). PLoS ONE, 10, Article ID: e0136944. https://doi.org/10.1371/journal.pone.0136944

Creswell, J. W. (2014). Qualitative, Quantitative and Mixed Methods Approaches. Sage.

Deliens, T., Deforche, B., De Bourdeaudhuij, I., \& Clarys, P. (2015). Determinants of Physical Activity and Sedentary Behaviour in University Students: A Qualitative Study Using Focus Group Discussions. BMC Public Health, 15, Article No. 201. https://doi.org/10.1186/s12889-015-1553-4

Dempsey, P., Strain, T., Khaw, K., Wareham, N., Brage, S., \& Wijndaele, K. (2020). Prospective Associations of Accelerometer-Measured Physical Activity and Sedentary Time with Incident Cardiovascular Disease, Cancer, and All-Cause Mortality. Circulation, 141, 1113-1115. https://doi.org/10.1161/CIRCULATIONAHA.119.043030

Economist Intelligence Unit (2019). Safe Cities Index 2019: Urban Security and Resilience in an Interconnected World. Economist Intelligence Unit.

Egli, T., Bland, H., Melton, B., \& Czech, D. (2011). Influence of Age, Sex, and Race on College Students' Exercise Motivation of Physical Activity. Journal of American College Health, 59, 399-406. https://doi.org/10.1080/07448481.2010.513074

Ekelund, U., Tarp, J., Steene-Johannessen, J., Hansen, B., Jefferis, B., Fagerland, M., Whincup, P., Diaz, K., Hooker, P., \& Chernofsky, A. (2019). Dose-Response Associations between Accelerometery Measured Physical Activity and Sedentary Time and All-Cause Mortality: Systematic Review and Harmonised Meta-Analysis. BMJ, 366, Article ID: 145170. https://doi.org/10.1136/bmj.14570

Faul, F., Erdfelder, E., Buchner, A., \& Lang, A. (2009). Statistical power analyses using $\mathrm{G}^{\star}$ Power 3.1: Tests for Correlation and Regression Analyses. Behavior Research Methods, 41, 1149-1160. https://doi.org/10.3758/BRM.41.4.1149

Gomersall, S., Rowlands, A., English, C., Maher, C., \& Olds, T. (2013). The Activitystat Hypothesis. Sports Medicine, 43, 135-149. https://doi.org/10.1007/s40279-012-0008-7 
Hartmann-Tews, I., \& Pfister, G. (2003). Sport and Women: Social Issues in International Perspective. Psychology Press.

Hashimoto, K. (2018). Japan's 'Super Global Universities' Scheme: Why Does the Number of 'Foreign' Students Matter? In A. Ata, L. Tran, \& I. Liyanage (Eds.). Educational Reciprocity and Adaptivity: International Students and Stakeholders (pp. 25-44). Routledge. https://doi.org/10.4324/9781315201412-2

Hastie, P., Hu, A., Liu, H., \& Zhou, S. (2020). Incorporating Sport Education within a Physical Education Sports Club in China. Curriculum Studies in Health and Physical Education, 11, 129-144. https://doi.org/10.1080/25742981.2020.1751668

Hirvensalo, M. \& Lintunen, T. (2011). Life-Course Perspective for Physical Activity and Sports Participation. European Review of Aging and Physical Activity, 8, 13-22. https://doi.org/10.1007/s11556-010-0076-3

Izumo, T., Kowata, H., \& Kawakita, H. (2007). A Study on the Present Condition of the Class of the Physical Education with Foreign Students at Universities in Japan: Focusing on the Actual Condition and Issues Regarding Class Management. College Physical Education, 4, 45-56.

James, W. (2008). WHO Recognition of the Global Obesity Epidemic. International Journal of Obesity, 32, S120-S126. https://doi.org/10.1038/ijo.2008.247

Japan Student Services Organization (2019). Results of an Annual Survey of International Students in Japan 2018. Japan Student Services Organization.

Kidokoro, T., Kohmura, Y., Fuku, N., Someya, Y., \& Suzuki, K. (2020). Secular Trends in the Grip Strength and Body Mass Index of Sport University Students between 1973 and 2016: J-Fit ${ }^{+}$Study. Journal of Exercise Science \& Fitness, 8, 21-30.

https://doi.org/10.1016/j.jesf.2019.08.002

Kilpatrick, M., Hebert, E., \& Bartholomew, J. (2005). College students' Motivation for Physical Activity: Differentiating Men's and Women's Motives for Sport Participation and Exercise. Journal of American College Health, 54, 87-94. https://doi.org/10.3200/JACH.54.2.87-94

Kwan, M., Cairney, J., Faulkner, G., \& Pullenayegum, E. (2012). Physical Activity and Other Health-Risk Behaviors during the Transition into Early Adulthood: A Longitudinal Cohort Study. American Journal of Preventive Medicine, 42, 14-20. https://doi.org/10.1016/j.amepre.2011.08.026

Lee, I., \& Paffenbarger, R. (2000). Associations of Light, Moderate, and Vigorous Intensity Physical Activity with Longevity: The Harvard Alumni Health Study. American Journal of Epidemiology, 151, 293-299.

https://doi.org/10.1093/oxfordjournals.aje.a010205

Matsushita, Y., Yoshiike, N., Kaneda, F., Yoshita, K., \& Takimoto, H. (2004). Trends in Childhood Obesity in Japan over the Last 25 Years from the National Nutrition Survey. Obesity Research, 12, 205-214. https://doi.org/10.1038/oby.2004.27

Ministry of Education, Culture, Sports, Science and Technology (MEXT) (2020). Top Global University Project. https://tgu.mext.go.jp/en/index.html

Mota-Pereira, J., Silverio, J., Carvalho, S., Ribeiro, J., Fonte, D., \& Ramos, J. (2011). Moderate Exercise Improves Depression Parameters in Treatment-Resistant Patients with Major Depressive Disorder. Journal of Psychiatric Research, 45, 1005-1011. https://doi.org/10.1016/j.jpsychires.2011.02.005

National Institute of Physical Education (2018). University Health and Physical Education Survey 2016. National Institute of Physical Education.

Rizki, D., \& Rachman, H. (2019). Healthy Lifestyle Behaviors: An Investigation of Stu- 
dents. In Proceedings of the 6th International Conference on Educational Research and Innovation (ICERI 2018) (pp. 157-161) Atlantis Press.

https://doi.org/10.2991/iceri-18.2019.86

Rose, H., \& McKinley, J. (2018). Japan's English-Medium Instruction Initiatives and the Globalization of Higher Education. Higher Education, 75, 111-129.

https://doi.org/10.1007/s10734-017-0125-1

Saint-Maurice, P. F., Coughlan, D., Kelly, S. P., Keadle, S. K., Cook, M. B., Carlson, S. A. et al. (2019). Association of Leisure-Time Physical Activity across the Adult Life Course with All-Cause and Cause-Specific Mortality. Journal of the American Medical Association, 2, Article. ID: e190355. https://doi.org/10.1001/jamanetworkopen.2019.0355

Sallis, J. F., Prochaska, J. J., \& Taylor, W. C. (2000). A Review of Correlates of Physical Activity of Children and Adolescents. Medicine \& Science in Sports \& Exercise, 32, 963-975. https://doi.org/10.1097/00005768-200005000-00014

Shafiei, L., Taymoori, P., Maleki, A., \& Sayehmiri, K. (2018). Environmental Interventions Based on the Health Belief Model and the Ecological-Social Model in the Continuation of Consumption of Rice, Free from Toxic Metals. Electronic Physician, 10, 6153-6163.

Shah, H., Dhami, H., \& Shah, T. (2016). Assessment of Physical Activity Level in Female Students at Residential College Using Global Physical Activity Questionnaire: A CrossSectional Analysis. International Journal of Current Research and Review, 8, 24-27.

Stamatakis, E., Ekelund, U., Ding, D., Hamer, M., Bauman, A. E., \& Lee, I.-M. (2019). Is the Time Right for Quantitative Public Health Guidelines on Sitting? A Narrative Review of Sedentary Behaviour Research Paradigms and Findings. British Journal of Sports Medicine, 53, 377-382. https://doi.org/10.1136/bjsports-2018-099131

Stelmach, M. (2018). Physical Activity Assessment Tools in Monitoring Physical Activity: The Global Physical Activity Questionnaire (GPAQ), the International Physical Activity Questionnaire (IPAQ) or Accelerometers-Choosing the Best Tools. Health Problems of Civilization, 12, 57-63. https://doi.org/10.5114/hpc.2018.74189

Sterdt, E., Sebastian, L., \& Ulla, W. (2014). Correlates of Physical Activity of Children and Adolescents: A Systematic Review of Reviews. Health Education Journal, 73, 72-89. https://doi.org/10.1177/0017896912469578

Suminski, R., Petosa R., Utter, A., \& Zhang, J. (2002). Physical Activity among Ethnically Diverse College Students. Journal of American College Health, 51, 75-80. https://doi.org/10.1080/07448480209596333

Tanaka, S. (2019). Status of Physical Activity in Japanese Adults and Children. Annals of Human Biology, 46, 305-310. https://doi.org/10.1080/03014460.2019.1635644

Telama, R., \& Yang, X. (2000). Decline of Physical Activity from Youth to Young Adulthood in Finland. Medicine \& Science in Sports \& Exercise, 32, 1617-1622. https://doi.org/10.1097/00005768-200009000-00015

Tomkinson, G. R., Lang, J. J., \& Tremblay, M. S. (2019). Temporal Trends in the Cardiorespiratory Fitness of Children and Adolescents Representing 19 High-Income and Upper Middle-Income Countries between 1981 and 2014. British Journal of Sports Medicine, 53, 478-486. https://doi.org/10.1136/bjsports-2017-097982

Trost, S., Owen, N., Bauman, A., Sallis, J., \& Brown, W. (2002). Correlates of Adults' Participation in Physical Activity: Review and Update. Medicine \& Science in Sports \& Exercise, 34, 1996-2001. https://doi.org/10.1097/00005768-200212000-00020

Warner, M., Robinson, J., Lennox, B., \& Lloyd, J. (2021). Long-Term Relationships between SFD Program Engagement, Physical Literacy, and Physical Activity Levels among Urban 
Youth Aged 6 - 12 Facing Barriers to Positive Development. Advances in Physical Education, 11, 424-439. https://doi.org/10.4236/ape.2021.114035

Wattanapisit, A., Krittanu, F., Udomsak, S., \& Surasak, V. (2016). Physical Activity among Medical Students in Southern Thailand: A Mixed Methods Study. BMJ Open, 6, Article ID: e013479. https://doi.org/10.1136/bmjopen-2016-013479

Wei, C., Koichi H., Kimiyo U., Kumiko F., Keiko M., \& Atsushi, U. (2012). Assessment of Health-Promoting Lifestyle Profile in Japanese University Students. Environmental Health and Preventive Medicine, 17, 222-227.

https://doi.org/10.1007/s12199-011-0244-8

World Health Organization (WHO) (2010). Global Physical Activity Questionnaire (GPAQ) Analysis Guide. World Health Organization. 